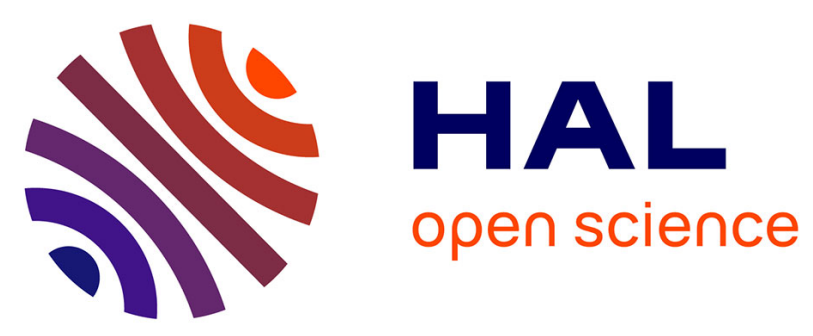

\title{
Surface damage on polycrystalline $\beta$-SiC by xenon ion irradiation at high fluence
}

\author{
J. Baillet, S. Gavarini, N. Millard-Pinard, V. Garnier, C. Peaucelle, X. \\ Jaurand, A. Duranti, C. Bernard, R. Rapegno, Sandrine Cardinal, et al.
}

\section{- To cite this version:}

J. Baillet, S. Gavarini, N. Millard-Pinard, V. Garnier, C. Peaucelle, et al.. Surface damage on polycrystalline $\beta$-SiC by xenon ion irradiation at high fluence. Journal of Nuclear Materials, 2018, 503, pp.140-150. 10.1016/j.jnucmat.2018.01.026 . cea-01701709

\section{HAL Id: cea-01701709 https://hal-cea.archives-ouvertes.fr/cea-01701709}

Submitted on 6 Feb 2018

HAL is a multi-disciplinary open access archive for the deposit and dissemination of scientific research documents, whether they are published or not. The documents may come from teaching and research institutions in France or abroad, or from public or private research centers.
L'archive ouverte pluridisciplinaire HAL, est destinée au dépôt et à la diffusion de documents scientifiques de niveau recherche, publiés ou non, émanant des établissements d'enseignement et de recherche français ou étrangers, des laboratoires publics ou privés. 


\section{Surface damage on polycrystalline $\beta$-SiC by xenon ion irradiation at high fluence}

J. Baillett ${ }^{a}$, S. Gavarini ${ }^{a, c}$, N. Millard-Pinard ${ }^{a}$, V. Garnier ${ }^{b}$, C. Peaucelle ${ }^{a}$, X. Jaurand ${ }^{c}$, A. Duranti ${ }^{a}$, C. Bernard ${ }^{a}$, R. Rapegno ${ }^{\text {a }}$, S. Cardinal ${ }^{\mathrm{b}}$, L. Escobar-Sawa ${ }^{\mathrm{a}}$, T. De Echave ${ }^{\mathrm{a}}$, B. Lanfant ${ }^{\mathrm{d}}$, Y. Leconte ${ }^{\mathrm{d}}$

${ }^{a}$ Univ Lyon, Université Lyon 1, CNRS/IN2P3, UMR5822, IPNL, F-69622 LYON, France

${ }^{\mathrm{b}}$ Univ Lyon, INSA de Lyon, MATEIS CNRS UMR5510, F-69621 Villeurbanne, France

${ }^{\mathrm{c}}$ Univ Lyon, Université Lyon 1, CT $\mu$, F-69622 VILLEURBANNE Cedex, France

${ }^{\mathrm{d}}$ CEA, IRAMIS, UMR-3685 NIMBE, F 91191 Gif-sur-Yvette, France

Summary:

Nano-grained $\beta$-silicon carbide ( $\beta$-SiC) pellets were prepared by Spark Plasma Sintering (SPS). These were implanted at room temperature with $800 \mathrm{keV}$ xenon at ion fluences of $5.10^{15}$ and $1.10^{17} \mathrm{~cm}^{-2}$. Microstructural modifications were studied by electronic microscopy (TEM and SEM) and xenon profiles were determined by Rutherford Backscattering Spectroscopy (RBS). A complete amorphization of the implanted area associated with a significant oxidation is observed for the highest fluence. Large xenon bubbles formed in the oxide phase are responsible of surface swelling. No significant gas release has been measured up to $10^{17}$ at. $\mathrm{cm}^{-2}$. A model is proposed to explain the different steps of the oxidation process and xenon bubbles formation as a function of ion fluence. 


\section{I- Introduction}

Silicon carbide ( $\mathrm{SiC}$ ) is considered for nuclear applications (in fusion reactors [1-15], Light Water Reactors (LWR's) and Boiling Water Reactors (BWR's) [1, 10, 13, 16- 18], Generation IV fission concepts [1-3, 9-10, 16, 17-21] and nuclear waste disposal, and immobilization/transmutation [16-17, 20, 22]) mainly due to its hightemperature endurance, high radiation tolerance, superior physical and chemical stability, fission product retention ability and inherent low-induced radioactivity in a neutron radiation environment [23-27]. SiC is also widely considered as a potential candidate for other high temperature (or severe environment) structural components in the energy [28-29], aerospace $[8,19,22,30]$ and semiconductor/electronic industries $[8,22,29$ $30,31]$.

For nuclear applications, $\mathrm{SiC}$ can be used as high-density monolithic CVD deposits to prevent fission product release (TRISO-coated particles in a VHTR (Very High Temperature Reactor) $[9,15,20]$, the innerrmost layer of LWR fuel cladding [1-2, 16, 32]) or as a composite, for example (SiC)-fiber-reinforced SiC matrix. $\mathrm{SiC} / \mathrm{SiC}_{\mathrm{f}}$ composites have been proposed for fuel rod cladding in future reactors, and also in current LWR's to improve oxidation resistance as a replacement for the current claddings of zirconium-based alloys [33].

For all the above-mentioned applications, there is a great need for experimental work in order to better understand the formation, accumulation and recovery from damage induced by irradiation with energetic particles in SiC material. A rather large number of papers were published in the last three decades on the damage production in $\mathrm{SiC}$ (see for instance [15, 34-35]). Nevertheless, there is a lack of data on the formation of bubbles and/or cavities resulting from the incorporation and agglomeration of heavy noble gas atoms produced during fission and alpha-decay of actinides. In fact, it has been shown that the creation of bubbles/cavities induces deleterious effects on the physical integrity of $\mathrm{SiC}$ (e.g. formation of cracks, surface swelling and exfoliation) used in a nuclear context [36-38]. Radioactive xenon isotopes are an important group of gaseous fission products and their retention in $\mathrm{SiC}$ is therefore of crucial importance for reactor safety. Little is known about xenon behavior in $\mathrm{SiC}$ but the solubility of this species is supposedly very low due to its atomic radius that defines its mobility in most materials. According to first principle calculations carried out by Charaf Eddin et al. [39], xenon atoms tend to remain in divacancies, with low formation energies. After that, the second best choice is silicon monovacancies. At high concentration, the formation of extended defects such as bubbles is expected. Recently, Friedland et al. [40] studied the diffusion of xenon in single- and poly-crystalline SiC. $360 \mathrm{keV}$ xenon ions were implanted in commercially-available 6H-SiC (single crystal) and CVD-SiC (3C-SiC crystallites with columnar grains) wafers at room temperature (RT) and also at $350{ }^{\circ} \mathrm{C}$ and $600{ }^{\circ} \mathrm{C}$. The RT implantation at a fluence of $1.10^{16}{\text { at. } \mathrm{cm}^{-2}}^{2}$ resulted in a complete amorphization of the material (amorphization threshold $\sim 0.2$ displacement per atom below $100{ }^{\circ} \mathrm{C}$ [41-42]). No diffusion or xenon loss was detected in the case of $6 \mathrm{H}-\mathrm{SiC}$ during annealing up to $1400^{\circ} \mathrm{C}$ whereas radiation damage dependent grain boundary diffusion was observed at $1300{ }^{\circ} \mathrm{C}$ in CVD-SiC. However, no information was given about the formation of bubbles or their distribution in the implanted material. The threshold concentration for xenon bubble formation in polycrystalline $\mathrm{SiC}$ is not reported in the literature to our knowledge. However, Velisa et al. [43] have studied the modifications of the 
microstructure of $6 \mathrm{H}-\mathrm{SiC}$ single crystals implanted with high concentrations of noble gas ions ( $\mathrm{He}$ and $\mathrm{Ar}$ ). They showed that a difference exists between the response of He- and Ar-implanted specimens. No gas bubbles were formed in single crystal after Ar irradiation at a fluence of $5.10^{16} \mathrm{at}^{-\mathrm{cm}^{-2}}\left(\mathrm{C}^{\mathrm{Ar}}{ }_{\max }=6.4\right.$ at. $\%$, dpa $\left.\mathrm{max}_{\max }=54\right)$ whereas He bubbles were clearly visible after implantation at a similar concentration near the ion projected range. This difference can be qualitatively explained by the experimental observation that the radiation tolerance of the material implanted with a high concentration of noble gases depends on the nature of these gases and particularly on their atomic radius.

This paper aims to investigate defect formation and final morphology due to noble gas implantation (xenon) into $\beta$-SiC polycrystals with fine-grained microstructure. The first section deals with the initial characterization of $\mathrm{SiC}$ polycrystals and the description of the ion implantation process. The changes occurring during xenon implantation in the microstructure, structure and composition of $\mathrm{SiC}$ are detailed in the second section. A discussion is proposed in the third section. A simplified but explanatory presentation of the results is summarized in schematic diagrams. The main similarities and differences existing in the damage mechanisms resulting from Xe ion implantation at high fluence in $\mathrm{SiC}$ (this work) and in $\mathrm{TiC}$ [44] are discussed in the second sub-section of the discussion section. 


\section{II- Experimental}

$\mathrm{SiC}$ nanopowders were synthesized by laser pyrolysis [45]. The complete protocol is described elsewhere [46]. Green bodies (2 g) were sintered by SPS (HPD25 FCT System GmbH, Germany). The sintering cycle applied was similar to the one in ref. [47] i.e. a pressure of $30 \mathrm{MPa}$ was kept constant until the temperature reached $1400{ }^{\circ} \mathrm{C}$. Then, the pressure was set at $100 \mathrm{MPa}$ until the end of the dwell time and released thereafter during the natural cooling. The dwell time was $6 \mathrm{~min}$ at a sintering temperature of $1850{ }^{\circ} \mathrm{C}$. The heating rate was set at $185^{\circ} \mathrm{C} / \mathrm{min}$ during the sintering cycle. Several samples were cut from each sintered body and were then mechanically polished down to micron scale with diamond paste. The final step of this protocol consisted in polishing on colloidal silica. The samples were then heated at $1000^{\circ} \mathrm{C}$ for $10 \mathrm{~h}$ under secondary vacuum $(\mathrm{P}<$ $5.10^{-6} \mathrm{mbar}$ ), in order to relax most of the strain induced by polishing the surface [54].

The surface of the as-prepared samples was observed by SEM (FEI@ Quanta 250 FEG ESEM). As can be seen in Fig. 1 a, grains cannot be distinguished easily on the SEM photographs, due to the lack of visible grain boundaries (even after thermal treatment at $1000{ }^{\circ} \mathrm{C}$ for $10 \mathrm{~h}$ ). Therefore, thin sections were prepared by FIB using a focused beam of gallium ions in order to study the structure of grains and grain boundaries by TEM (2100F 200KV JEOL apparatus) (see fig. 1b).
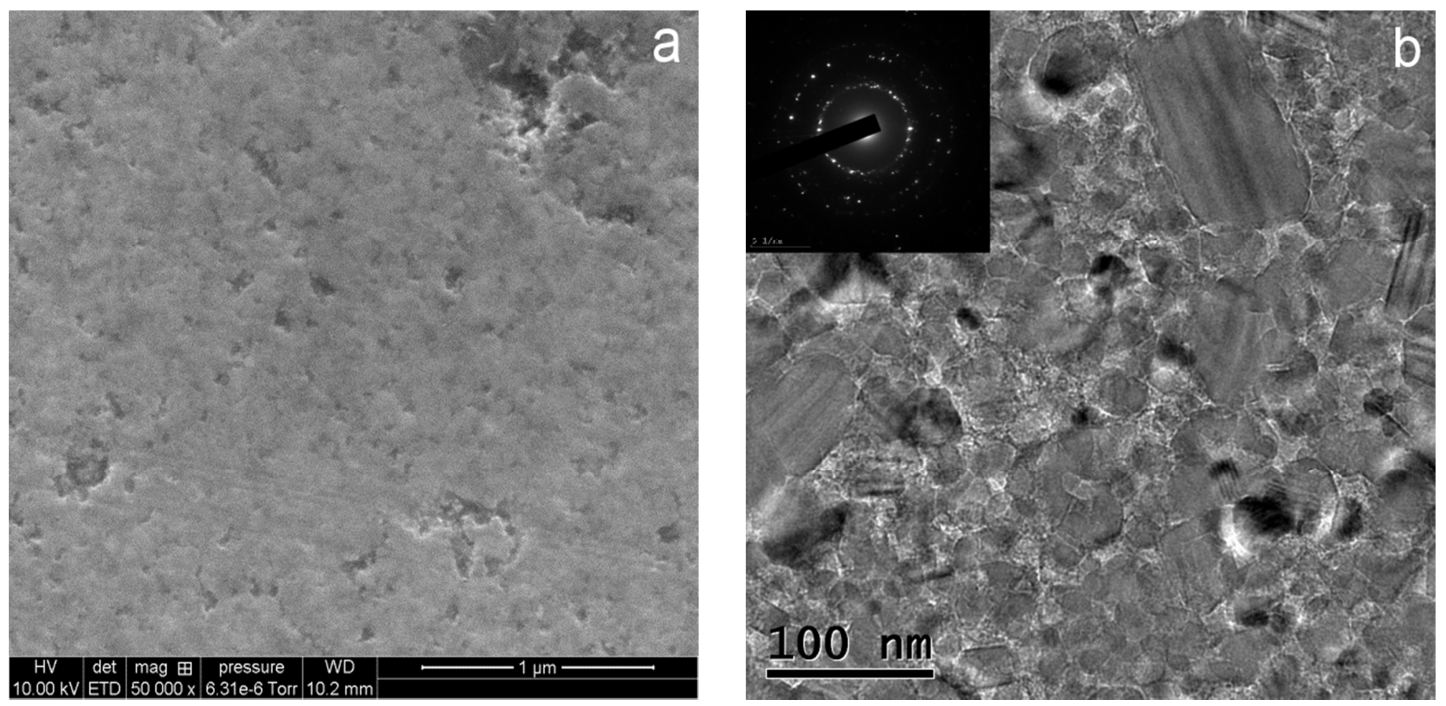

Figure 1: a) SEM micrograph of SiC surface after polishing and thermal treatment at $1000^{\circ} \mathrm{C}$ for $10 \mathrm{~h}$ and $\left.\mathrm{b}\right) \mathrm{TEM}$ image of a cross-section obtained by FIB. The upper left inset figure shows the electron diffraction pattern for the corresponding region.

Mean values of grain size were calculated by the average linear intercept method in the horizontal and vertical directions on 660 grains on several TEM photographs (See Fig. 1 b). ImageJ analysis software [48] was used for this purpose and the resulting histogram is given in Fig.2. The average grain size is $62.7 \mathrm{~nm}$ with a standard deviation of $26.3 \mathrm{~nm}$. Most grains have a size of about $60 \mathrm{~nm}$, but some are larger at about $100 \mathrm{~nm}$ to $200 \mathrm{~nm}$. 


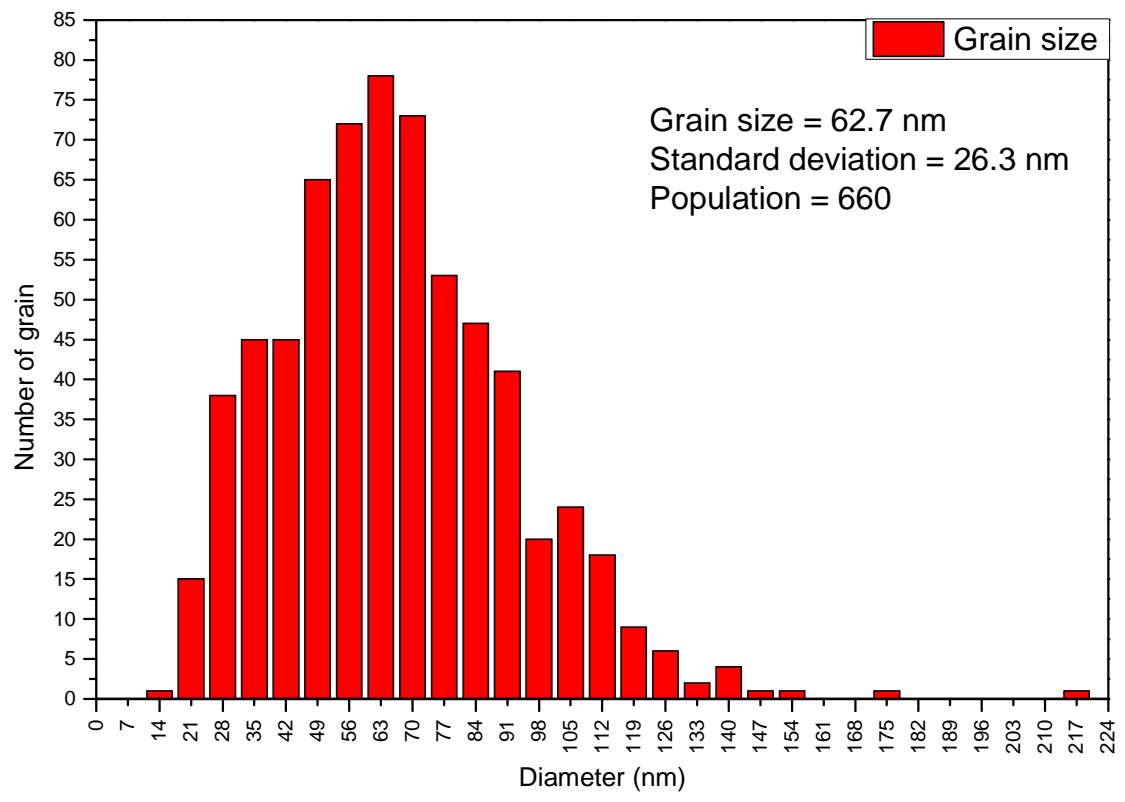

Figure 2: Grain size distribution of the sintered material.

It has to be noted that the HR-TEM observations (Fig. 3) clearly show the presence of free carbon between grains (white rectangles in Fig. 3). Those graphene-like structures are composed of about 4 to 5 layers.

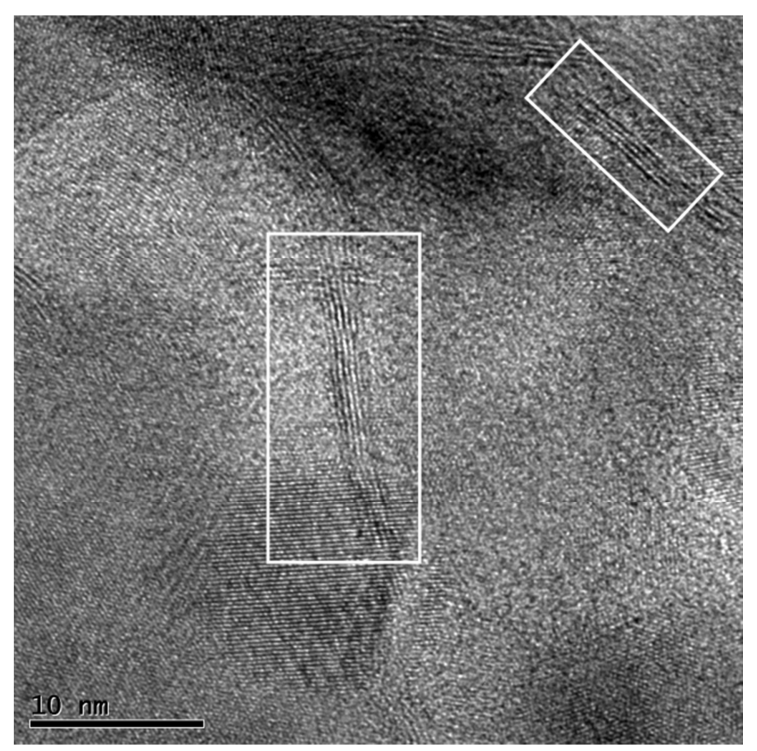

Figure 3: HR-TEM image of SiC cross-section

Bulk density was measured using the Archimedes method following the C373-88(2006) ASTM standard test method. The relative density (density of the sintered part compared to the theoretical density) was calculated and was found to be $94 \% \pm 0.3 \%$.

The chemical composition of the sintered bodies was determined by ion beam analysis using a $4 \mathrm{MV}$ the Van de Graaff accelerator of the Institut for Nuclear Physics of Lyon. Classical RBS was used to quantify silicon with an incident $\alpha$ beam of $2.5 \mathrm{MeV}$ and an intensity of about $20 \mathrm{nA}$. Beam spot dimensions on the sample were about $1 \mathrm{~mm}^{2}$ and the detection angle was $172^{\circ}$. SIMNRA $6.04^{\circledR}$ software [49] was used to deduce 
depth profiles from experimental spectra. Note that with $\mathrm{SiC}$ material, the depth resolution of the RBS technique, using a few $\mathrm{MeV} \alpha$ particles, is about 15-20 nm from the surface (from RESOLNRA 1.0 program [50]). Carbon and oxygen content in the material were determined using $5.7 \mathrm{MeV}$ and $7.5 \mathrm{MeV}$ incident $\alpha$ energies, respectively (non-Rutherford cross-sections [51]). The following stoichiometry was obtained for sintered bodies: $\mathrm{SiC}_{102} \mathrm{O}_{01}$ (composition after the first $10 \mathrm{~nm}$ and the classical oxygen surface peak).

The specimens were implanted with $800 \mathrm{keV} \mathrm{Xe}^{++}$ions at room temperature (RT) at fluences of $5.10^{15}$ at.cm ${ }^{-2}$ (Xe beam current density $\left.\mathrm{i}=0.278 \mu \mathrm{A} \cdot \mathrm{cm}^{-2}\right)$ and $10^{17}$ at. $\mathrm{cm}^{-2}\left(\mathrm{i}=2.54 \mu \mathrm{A} \cdot \mathrm{cm}^{-2}\right)$ in the Institute of Nuclear Physics of Lyon. Fig. 4 shows the theoretical damage distribution created by Xe ions and the distribution of $\mathrm{Xe}$ as a function of depth. The values of dpa (displacement per atom) and Xe concentration were converted from the results calculated by the SRIM-2008 ${ }^{\circledR}$ code [52]. In the case of the sample irradiated with Xe ions at a fluence of $10^{17}$ at.cm ${ }^{-2}$, the dpa profile is simply 20 times higher than that of the $5.10^{15}$ at.cm ${ }^{-2}$ implanted samples in the entire depth range, since the dpa value is proportional to ion fluence only if ion species and acceleration voltage are fixed. Hereafter, the $5.10^{15}$ at.cm ${ }^{-2}$ and $1.10^{17}$ at. $\mathrm{cm}^{-2}$ implanted samples are termed as "low fluence" (or $\Phi_{1}$ ) and "high fluence" (or $\Phi_{2}$ ) samples, respectively. In the following section, the RBS technique will be used to determine experimental xenon depth profiles using $2.5 \mathrm{MeV} \alpha$-particles.

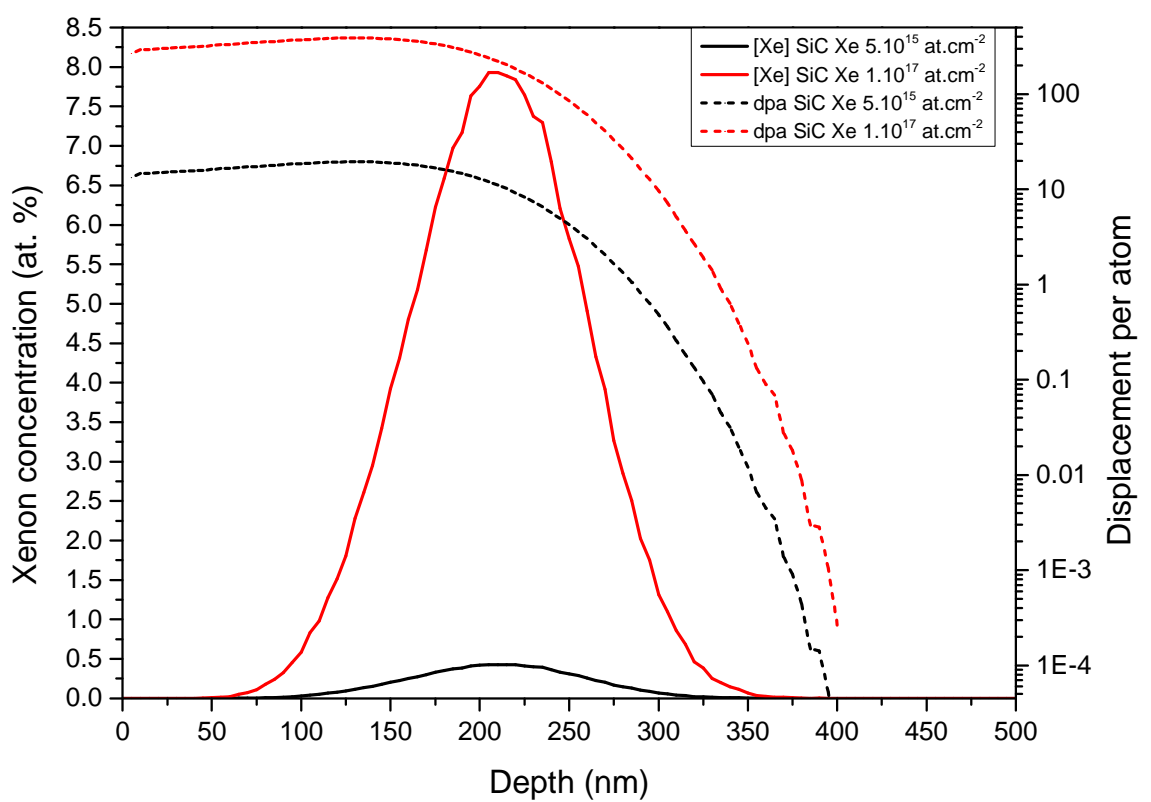

Figure 4: Xenon depth profiles and corresponding dpa profiles, deduced from SRIM-2008 ${ }^{\circledR}$ simulations, for the two fluences $\Phi_{I}$ (low fluence) and $\Phi_{2}$ (high fluence). 


\section{III- Results}

\section{III-1 Surface morphology, structure and microstructure}

The surface of SiC pellets was observed by SEM after ion implantation at both fluences (see Fig. 5 a) and $5 \mathrm{~b}$ )). As can be seen, little modification occurred after irradiation at $\Phi_{1}=5.10^{15}$ at.cm $^{-2}$ with only a slight smoothing of the surface and the disappearance of any visible porosity. For $\Phi_{2}=1.10^{17}$ at. $\mathrm{cm}^{-2}$, the surface aspect is radically modified with a massive swelling and a huge increase of roughness (Fig. 5 b)). Thin sections of these samples were prepared by FIB and were then observed by TEM (Fig. 6 a)) and STEM (Fig. 6 b)).
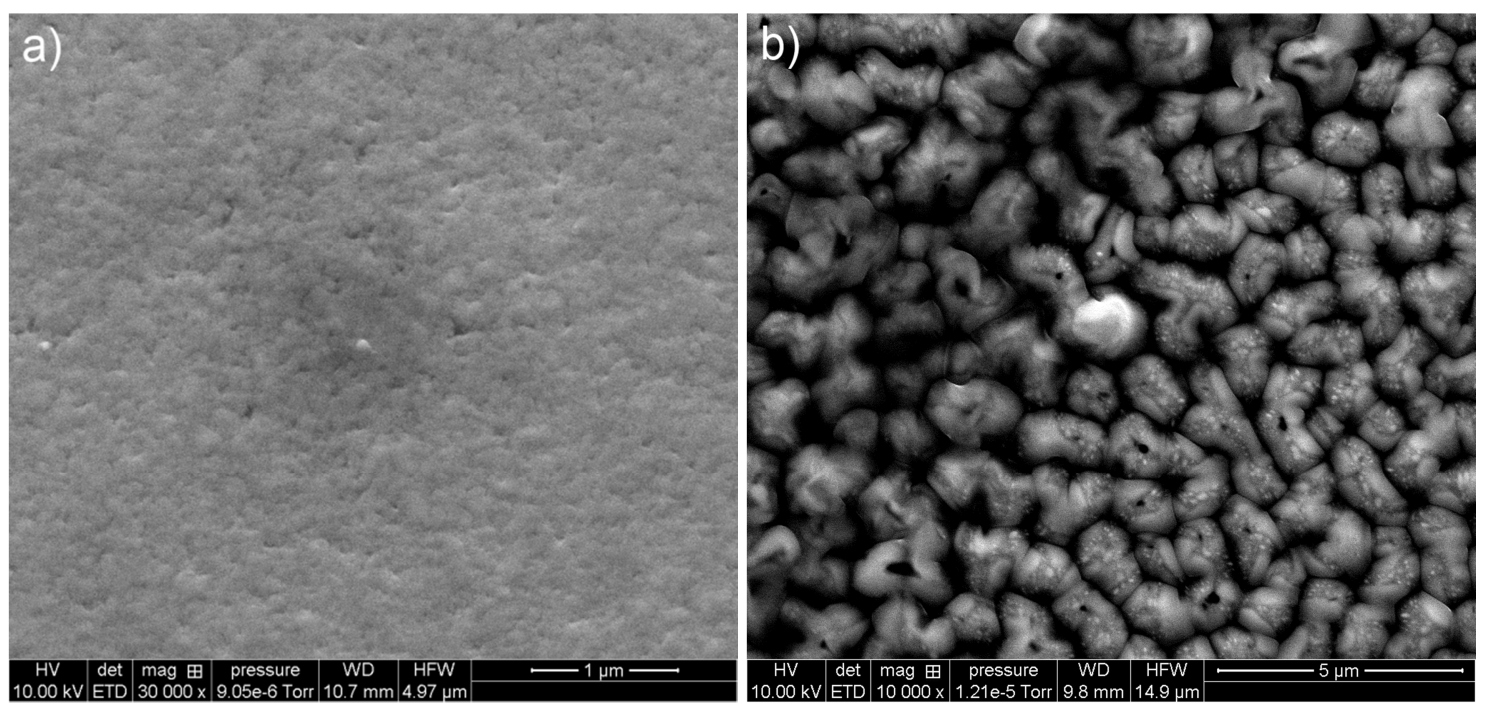

Figure 5: SEM images of the SiC surface after RT xenon implantation at a) $\Phi_{l}$ and b) $\Phi_{2}$

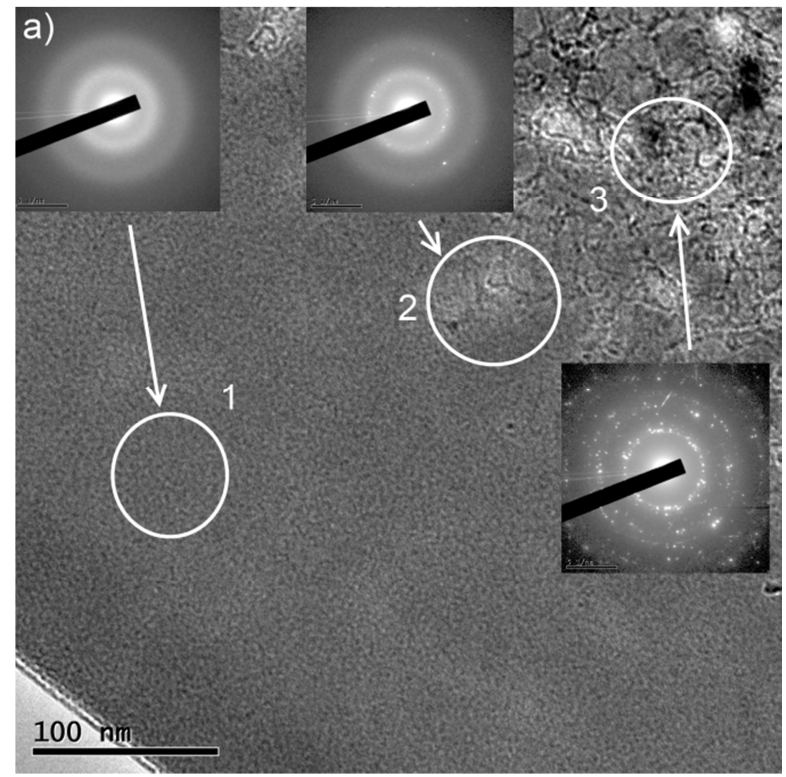




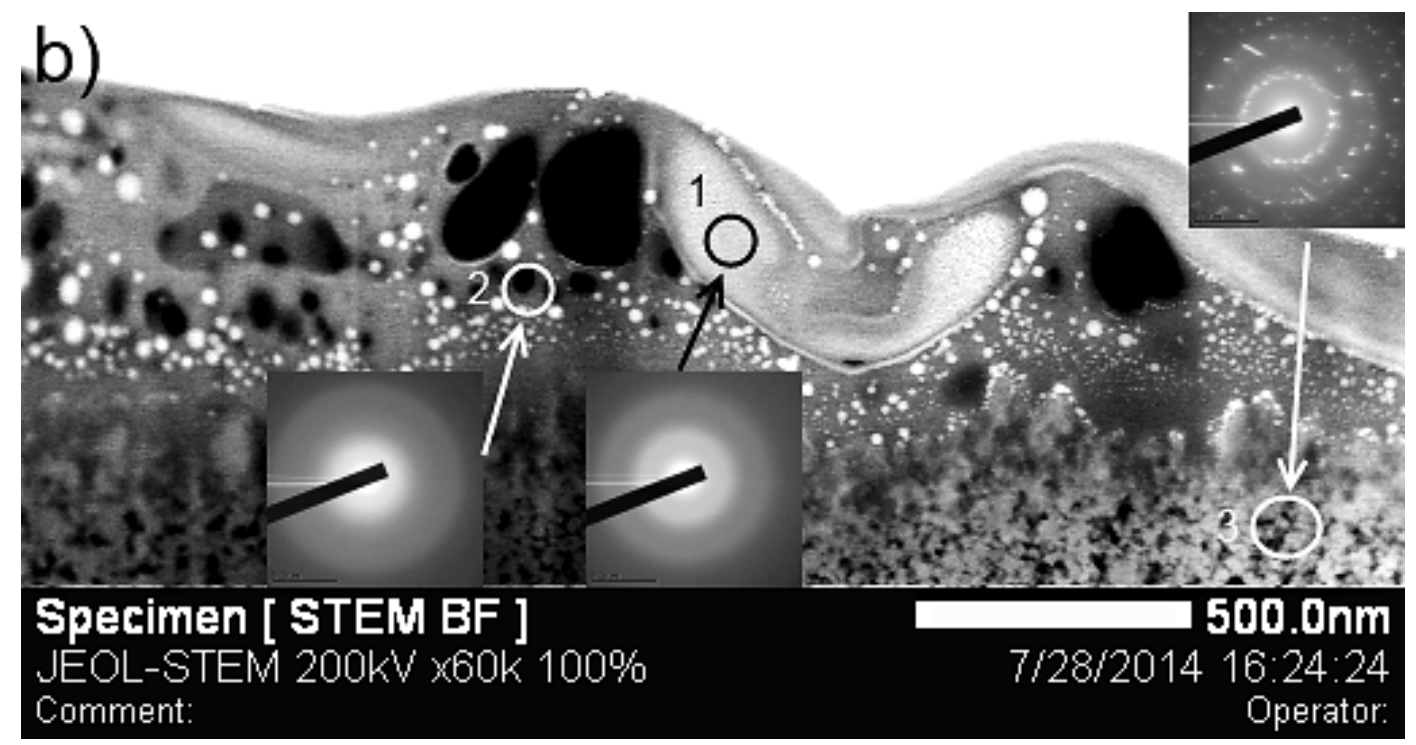

Figure 6: a) TEM image of the SiC surface after xenon RT implantation $\Phi_{1}$ and b) STEM image after implantation at $\Phi_{2}$

By SAED-TEM and for both fluences, the implanted area was shown to be amorphous (see diffractograms in the inserts of Fig. 6 a) and 6 b)), but in the case of the highest fluence a rather heterogeneous morphology is observed (Fig. 6 b)). Diffractograms of regions 1 and 2 (circles in Fig. 6 b)) both correspond to an amorphous material but with rings of different diameters indicating the presence of two distinct phases. Moreover, large xenon bubbles (bright points) and empty cavities (dark holes) are present in the implanted area. The empty cavities were formerly xenon bubbles, but the FIB sampling empties them. This means that bubble formation and growth take place during Xe implantation. Elongated cavities are formed near the surface (up to $250 \mathrm{~nm}$ for the longest axis) and appear responsible for local swelling. Most of the large cavities (diameter > 30 $\mathrm{nm}$ ) are empty but it is very likely that they contained xenon before FIB sampling. Smaller bubbles (mean diameter $<5 \mathrm{~nm}$ ) are mostly located at deeper depths. However, some regions do not present large bubbles (region 1 on Fig. 6 b)). If we focus on these areas (Fig. 7), then only nanobubbles $(<1-2 \mathrm{~nm}$ ) are visible. Bubbles coalescence and growth is therefore different between region 1 and 2 of Fig. 6 b).

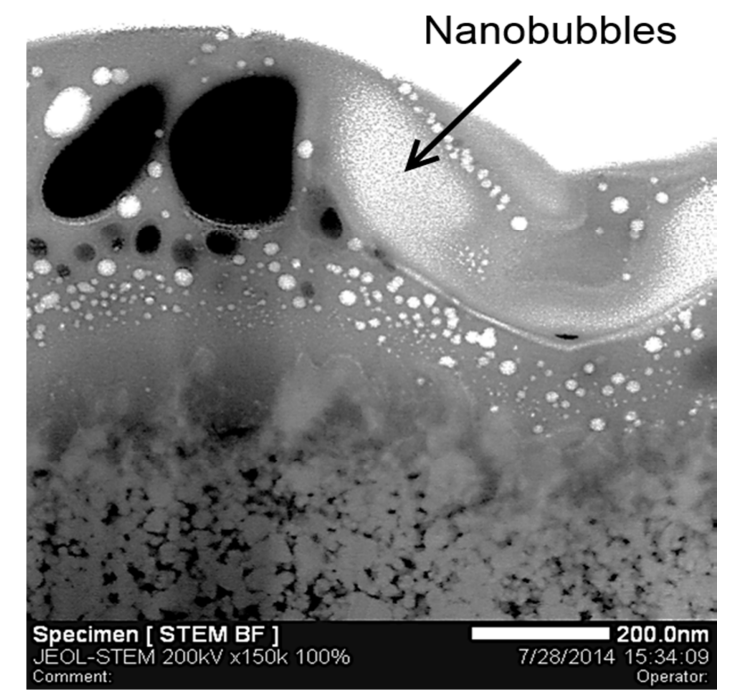

Figure 7: STEM image of region 1 after implantation at $\Phi_{2}$. Nanobubbles are clearly visible. 
The STEM micrograph of Fig. 6 b) was segmented using ImageJ software [48] into a binary image. The bubble/cavity diameter histogram (bright points and empty cavities of Fig. 6 b)) is shown in Fig. 8 a) and in order to illustrate this, the best ellipse fit is drawn in Fig. 8 b) for a given area of the previous micrograph.
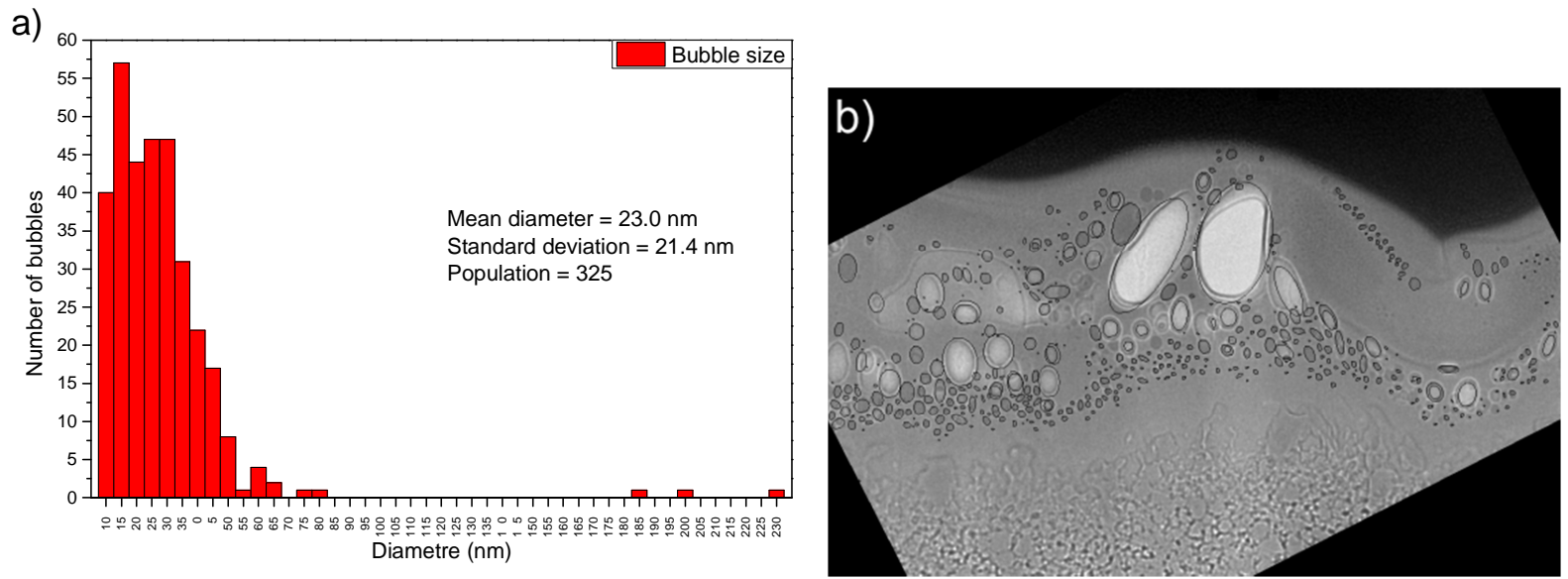

Figure 8: a) Bubble and cavity diameter histogram and b) best ellipse fit of binary image obtained after image segmentation (ImageJ software [48])

The mean diameter of the bubbles filled with xenon and calculated under spherical approximation is $17.5 \mathrm{~nm}$ with a standard deviation of $11.9 \mathrm{~nm}$. Note that very small bubbles (diameter $<2 \mathrm{~nm}$ ) were not detected after segmentation and thus the previous mean diameter value is overestimated. The mean roundness $\mathrm{r}=\frac{4 \times A}{\pi \times(X)^{2}}$ (where $\mathrm{A}$ is the area and $\mathrm{X}$ the major axis of the ellipse) was found to be 0.754 ( 1 for a circle) with a standard deviation of 0.191 .

\section{III-2 Elemental composition}

STEM-EDX analysis of the implanted area was performed and the resulting elemental mapping is shown in Figs. 9 and 10 for $\Phi_{1}$ and $\Phi_{2}$, respectively. As can be seen in Fig. 9, the irradiation at $\Phi_{1}$ resulted in slight O-enrichment at the interface between the irradiated and non-irradiated region ( $300 \mathrm{~nm}$ from the surface). Xenon is visible (even slightly) at this fluence at a depth concordant with the initial range $(\mathrm{Rp} \approx 200 \mathrm{~nm}+$ $\sim 20 \mathrm{~nm}$ ) meaning that a slight swelling has occurred. The dark regions observed in the non-irradiated region on the STEM image (free carbon + porosity) are no longer visible in the implanted region due to amorphization, induced swelling and ballistic mixing. For $\Phi_{2}$ (Fig. 10), elemental mapping confirmed the presence of xenon bubbles in the irradiated region, the largest cavities being empty as indicated previously. On the Si- and Cimages, a clear region is observed (upper-right) corresponding to elemental enrichment compared to the rest of the implanted region which is globally O-enriched. This distribution of the elements can be interpreted in terms of isolated islands of remaining $\mathrm{SiC}$. These are separated from the non-irradiated $\mathrm{SiC}$ region by an oxide layer (amorphous $\mathrm{SiO}_{2}$ ). On the one hand, large empty or filled bubbles (from 10 to $300 \mathrm{~nm}$ ) are located exclusively in the oxide phase. On the other hand, homogeneous nanometric bubbles are more likely to be present in the $\mathrm{SiC}$ islands. The two huge cavities observed in Fig. 6 b) are responsible for the deformation of the surface at that location. Thus, a clear correlation can be made between the surface morphology observed in Fig. 5 b), the consequent swelling of the surface and the presence of these huge bubbles beneath it. 

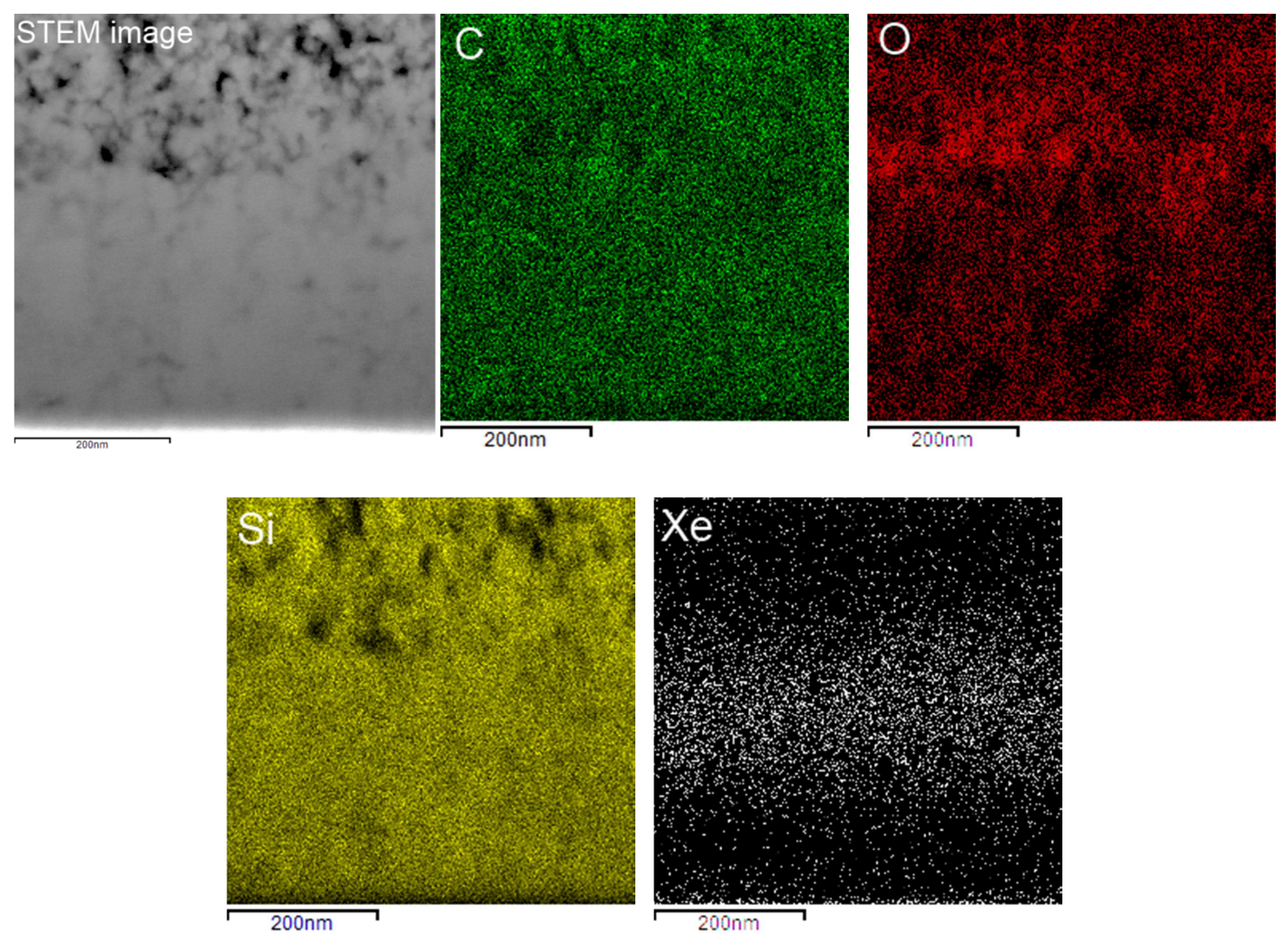

Figure 9: Elemental mapping of the implanted area obtained by STEM-EDX after xenon irradiation at $\Phi_{1 .}$
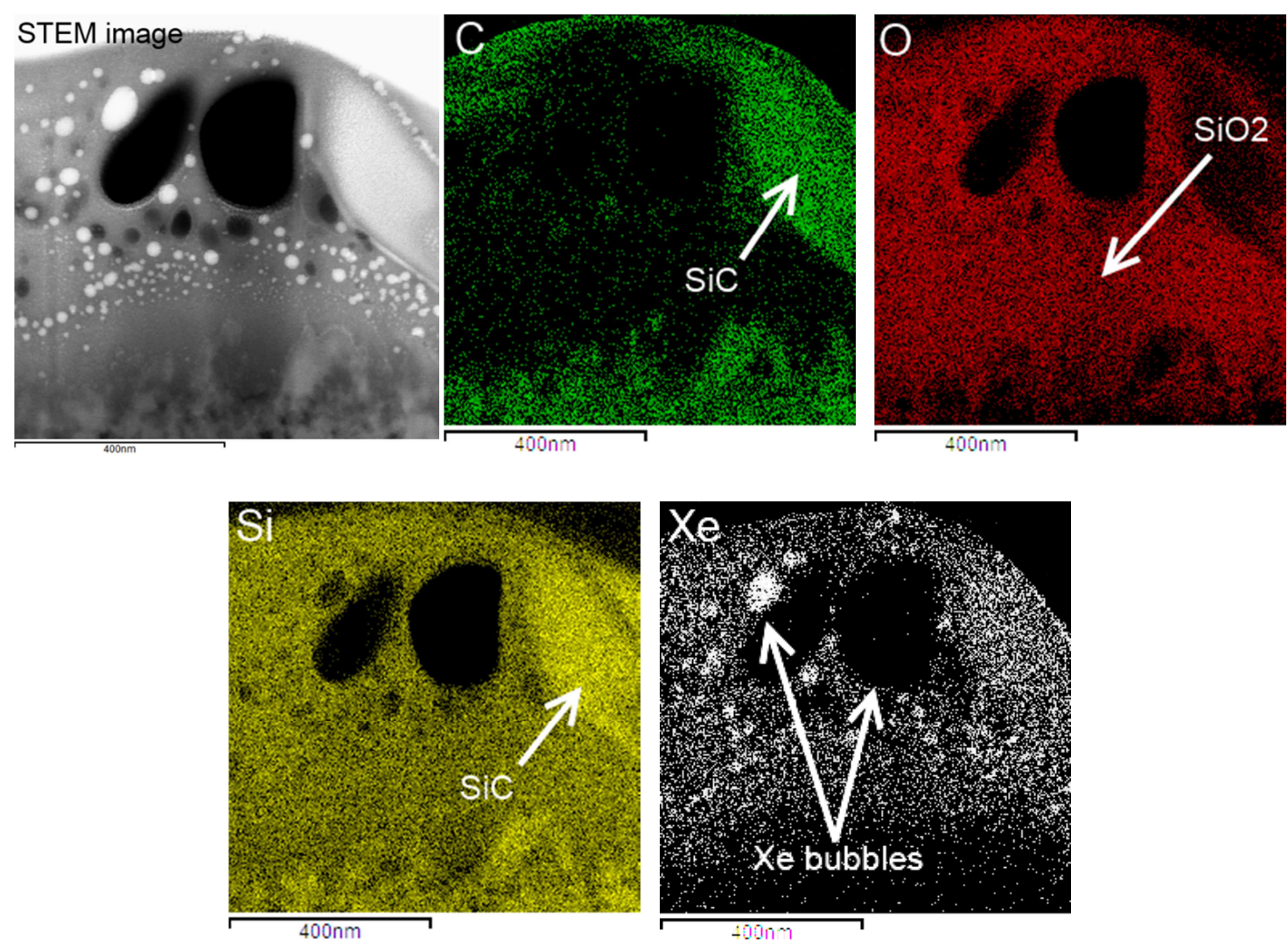

Figure 10: Elemental mapping of the implanted area obtained by STEM-EDX after xenon irradiation at $\Phi_{2 .}$ 


\section{III-3 Xenon profiles}

Xenon profiles were obtained by RBS and were compared to SRIM simulations for both fluences (Fig. 11).

a)

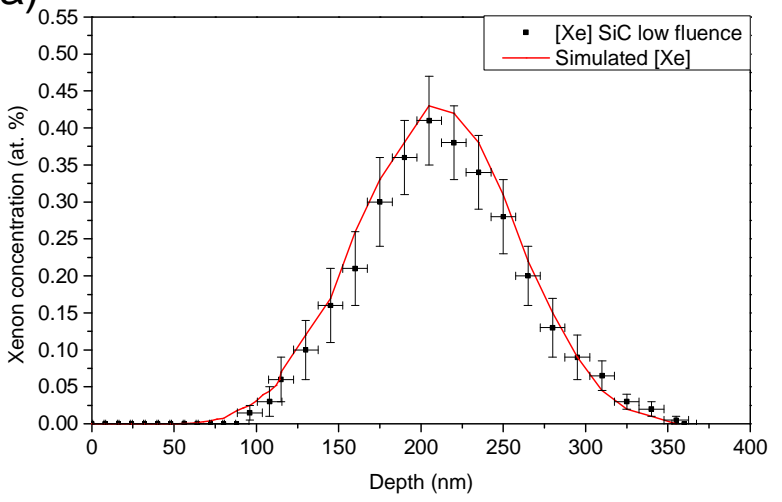

b)

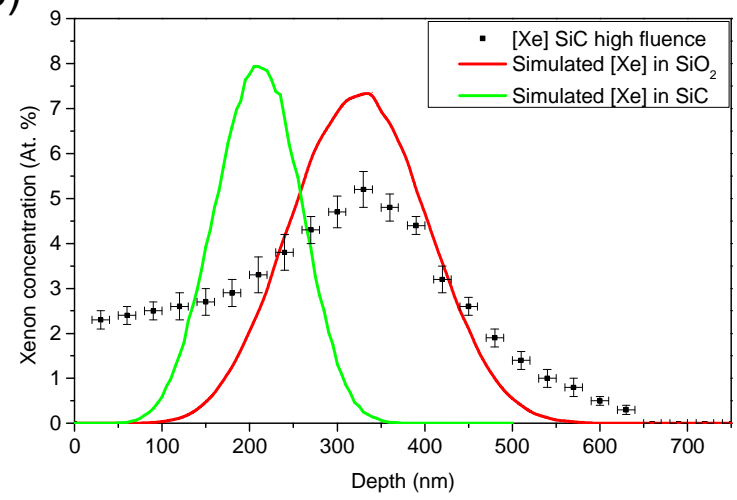

Figure 11: Xenon experimental depth profiles from RBS analysis and the corresponding theoretical profiles deduced from SRIM2008 ${ }^{\circledR}$ software, for the two fluences: a) low and b) high fluence. $\Phi_{2}$ profiles were obtained considering $\mathrm{SiO}_{2}$ as the implanted material $\left(\rho=2.2{\mathrm{~g} . \mathrm{cm}^{-3}}^{-3}\right.$ red curve). The green curve indicates the simulated xenon profile in pure SiC.

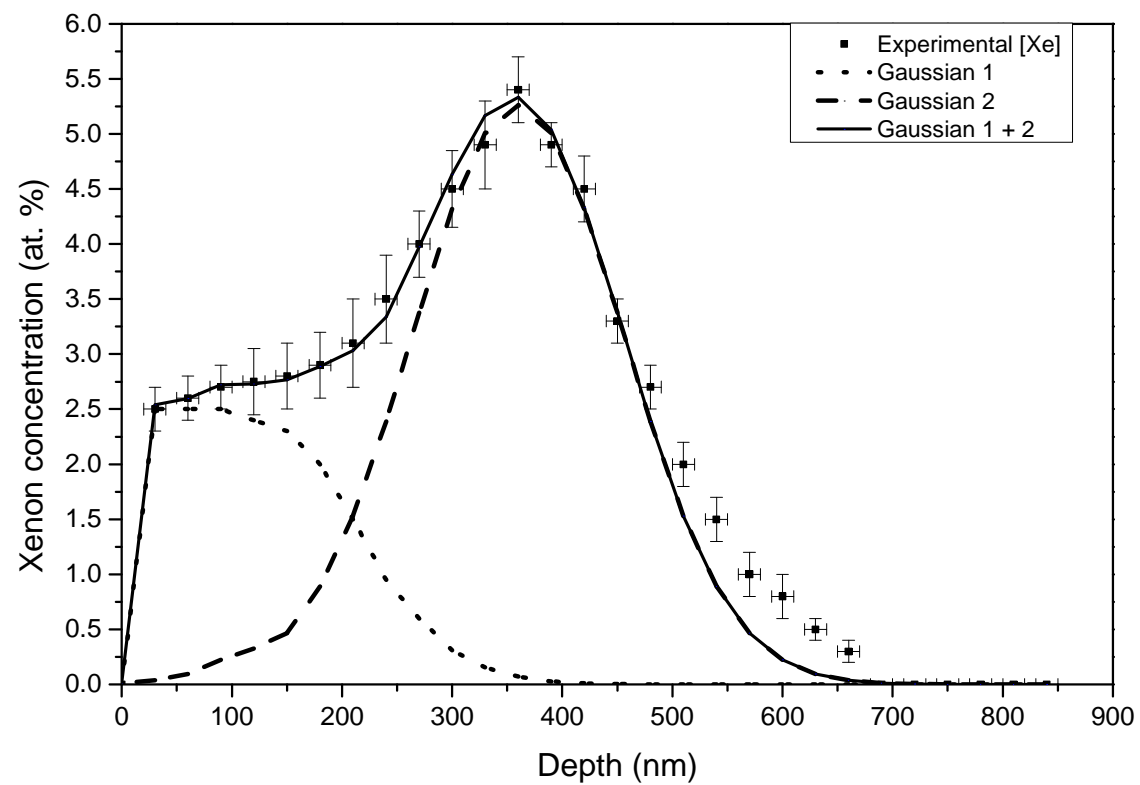

Figure 12: Experimental depth profiles for xenon for the $\Phi_{2}$ sample together with the Gaussian fitting.

Depth profiles deduced from RBS analysis are initially obtained as a function of the areal density $\left(10^{15}\right.$ at. $\left.\mathrm{cm}^{-2}\right)$ using SIMNRA software [49]. In order to obtain a length in SI units, the areal density has to be converted into a length unit using the material density. For $\Phi_{1}$, a density similar to SiC was assumed

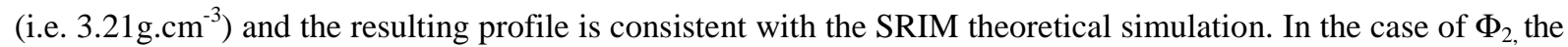
situation is more complex because the density of the material is not known precisely due to the presence of several phases (amorphous $\mathrm{SiC}+\mathrm{SiO}_{2}$ ) and xenon bubbles in the implanted area. Nevertheless, a density similar to $\mathrm{SiO}_{2}$ was assumed $\left(\rho=2.2 \mathrm{~g} \cdot \mathrm{cm}^{-3}\right)$ for the first approximation. The resulting curve is shown in Fig. $\left.11 \mathrm{~b}\right)$ and is compared with the SRIM simulation (also calculated assuming $\mathrm{SiO}_{2}$ as the implanted material). The 
experimental profile exhibits a peak located at a depth of about $360 \mathrm{~nm}$ as predicted by SRIM. However, it also shows a pronounced tail toward the surface. This profile can by fitted using two Gaussian signals as shown in Fig. 12. The nearest signal to the surface (dotted curve) has a maximum located in the first $100 \mathrm{~nm}$ while that of the second Gaussian (dashed curve) is near $360 \mathrm{~nm}$ (i.e. theoretical $\mathrm{R}_{\mathrm{p}}\left(\mathrm{Xe}\right.$ ) in $\mathrm{SiO}_{2}$ ). The xenon experimental profile has been superimposed on a TEM micrograph to illustrate the correspondence between the xenon mean profile and surface morphology (Fig. 13). A good correlation is found even if the area observed by TEM cannot be regarded as representative of the whole surface. However, based on this comparison, it seems reasonable to assume that peak 1 in the previous fit is mainly associated with xenon in the huge bubbles and in SiC islands (near the surface) whereas peak 2 better matches the population of smaller bubbles located at a depth near $\mathrm{R}_{\mathrm{p}}(\mathrm{Xe})_{\mathrm{SiO} 2}$.

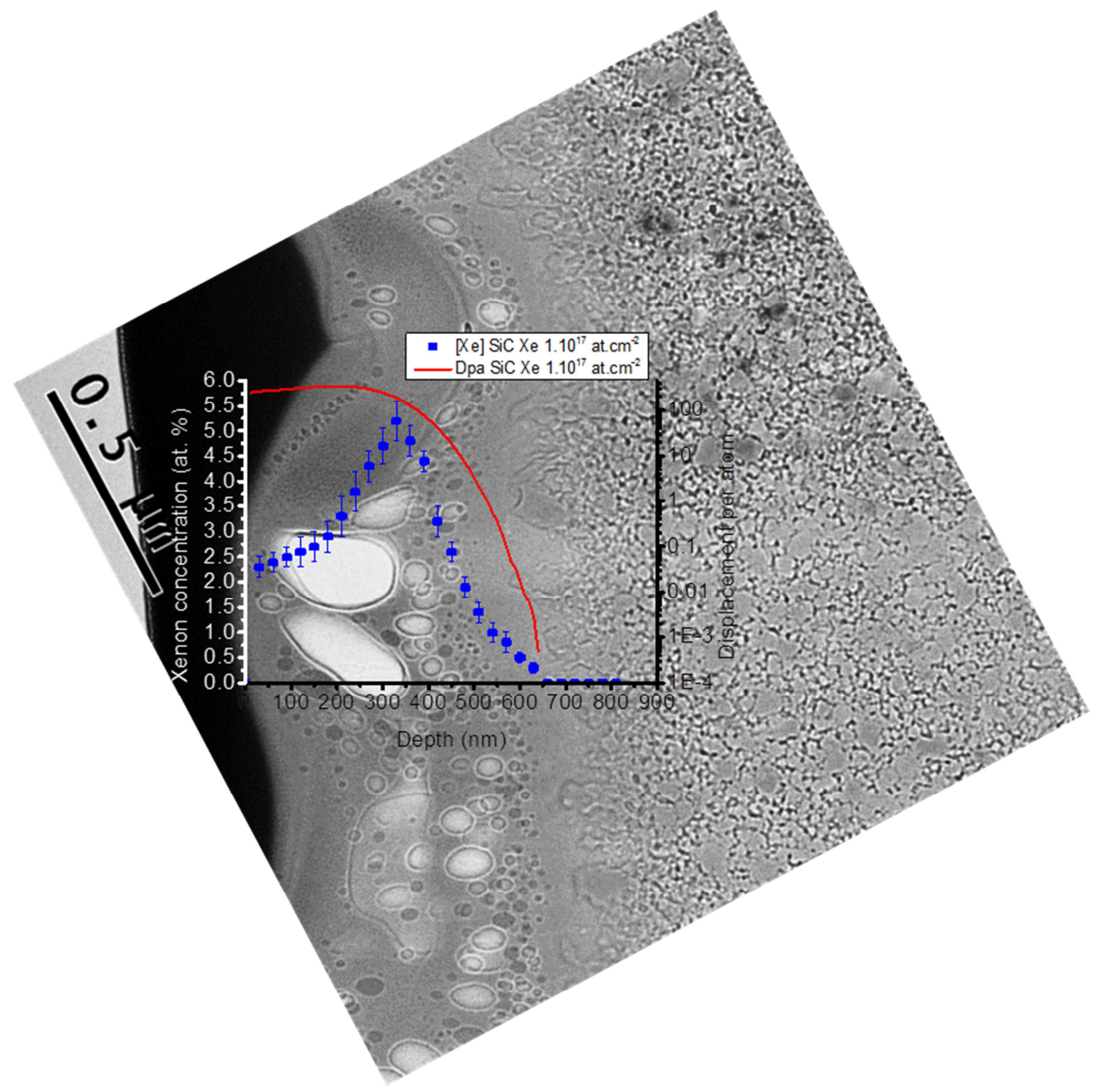

Figure 13: Superposition of the TEM micrograph and experimental xenon depth profile deduced from RBS analysis assuming a density similar to $\mathrm{SiO}_{2}$ 


\section{IV- Discussion}

The irradiation at an ion fluence of $\Phi_{1}=5.10^{15}$ at. $\mathrm{cm}^{-2}$ results in a complete amorphization of the material (see diffractogram in Fig. 6 a) region 1). In fact in Fig. 4, we can see that the dpa values calculated by the SRIM-2008 code for $\Phi_{1}$ fluence are 13, close to the surface, and 20, for the maximum dpa located at $150 \mathrm{~nm}$. These values are higher than the critical dpa value of $\sim 0.2$ for amorphization of $\mathrm{SiC}$ as given in the literature [41-42].

Slight oxidation of the material occurs at the interface between the irradiated and non-irradiated zones (see the oxygen map in Fig. 9). This oxidation is surprising for two reasons. Firstly, during the RT implantation, the sample temperature, measured with a thermocouple close to the sample, does not exceed $323 \mathrm{~K}\left(50{ }^{\circ} \mathrm{C}\right)$ (cooled sample holder). However, the local temperature in the implanted zone is probably slightly higher but should not be more than a few hundred Celsius. Secondly, the vacuum is maintained below $5.10^{-6}$ mbar during the process, which means that the oxygen partial pressure is always less than $10^{-6} \mathrm{mbar}$, which is sufficiently low to avoid oxidation even at several hundred degrees Celsius. The oxidation can also be explained by the postsintering thermal treatment. As indicated previously, the samples were heated at $1000^{\circ} \mathrm{C}$ for $10 \mathrm{~h}$ under a vacuum below $5.10^{-6}$ mbar just before implantation in order to relieve the stress caused by the polishing step. However, this primary treatment did not result in any significant oxidation of the samples that could have been observed by DRX or RBS. We can therefore assume that the considerable oxidation which occurred during the implantation process is largely due to radiation damage generated by xenon ions. Such oxidation due to irradiation effects has already been seen for SiC. For example, Muto et al. [53] have shown that $\mathrm{SiC}$ thin foil specimens were subject to considerable surface oxidation during TEM observation at $290 \mathrm{~K}$ (focused electron beam of $1 \mathrm{MV}$ and fluence of about $2 \mathrm{dpa}$ ) and the amount of oxygen uptake was increased with the structural disordering. In our case, the high damage level obtained after $\Phi_{2}$, results in severe oxidation of the irradiated band. Local heating of the surface is also suspected as being responsible for the oxidation. In fact, a current density of $2.54 \mu \mathrm{A} . \mathrm{cm}^{-2} \mathrm{can}$ increase the surface temperature. However, the temperature does not exceed $300{ }^{\circ} \mathrm{C}$ because above this value, no amorphization of $\mathrm{SiC}$ occurs [41]. We can therefore conclude that oxidation under irradiation could play a crucial role in the behavior of $\mathrm{SiC}$ material in nuclear conditions as traces of oxygen are likely to be present in the vicinity of core and structural materials.

Concerning xenon, no bubbles were observed at $\Phi_{1}\left([\mathrm{Xe}]_{\max }=0.42\right.$ at. \%). Velisa et al. [43] have also shown that no gas bubbles were formed in single crystals after irradiation with argon ions at a fluence of $5.10^{16}$ at. $^{-2}\left(\mathrm{C}^{\mathrm{Ar}}{ }_{\max }=6.4\right.$ at. \%, $\left.\mathrm{dpa}_{\max }=54\right)$. In fact, both argon and xenon atoms are expected to be slowly mobile in $\mathrm{SiC}$ at $\mathrm{RT}$ which explains the absence of visible gas bubbles at such relatively low fluence (no coalescence). At $\Phi_{2}$, result interpretation is more difficult because of the severe SiC oxidation. For SiC islands, only nanobubbles were observed, which means that the bubble formation threshold has been reached $\left([\mathrm{Xe}]_{\max }=7.93\right.$ at. \%). Large bubbles were found in the oxide phase. It can therefore be deduced that Xe mobility is very different in $\mathrm{SiO}_{2}$ than in $\mathrm{SiC}$. In the oxide, the higher mobility induces significant Xe coalescence which therefore leads to significant swelling.

The largest bubbles are systematically located very close to the surface whereas small and mediumsized bubbles are deeper. This shift in xenon bubble position was already observed by Naas et al [54] in the case 
of amorphous $\mathrm{SiO}_{2}$ irradiated with $300 \mathrm{keV}$ xenon ions at a fluence of $1.10^{16}$ at.cm ${ }^{-2}$. These authors reported a shift of the xenon peak toward the vacancy peak position $\left(\mathrm{R}_{\mathrm{p}}(\mathrm{V})\right)$ during implantation, which may approximately correspond to our dpa maximum here (see Fig. 4). In fact, xenon appears to be pumped from $R_{p}(X e)$ to $R_{p}(V)$ because of the formation of very stable $\mathrm{Xe}_{\mathrm{m}} \mathrm{V}_{\mathrm{n}}$ complexes near $\mathrm{R}_{\mathrm{p}}(\mathrm{V})$, which can be considered as bubble precursors. Note that these authors worked on amorphous thermally-grown $\mathrm{SiO}_{2}$ layers and therefore the observed xenon bubbles have a spherical shape. In our case, bubble coalescence occurs mainly in the $\mathrm{SiO}_{2}$ phase and much less in the $\mathrm{SiC}$ islands. This situation leads to bubble elongation (long axis quasi-normal to the surface) and very heterogeneous swelling of the surface (Fig. 5 b).

It is important to point out that no xenon release was observed at either fluence despite the significant structural and compositional changes in the implanted band. Amorphization and oxidation of SiC led to an amorphous $\mathrm{SiO}_{2}$ phase which can support significant swelling without any gas release.

From our results, the following schematic is proposed for the progressive transformation of the material during the irradiation process (Fig. 14). For clarity, three symbolic steps are shown in the diagram depending on the fluence; although in reality the evolution of the surface is assumed to be continuous.

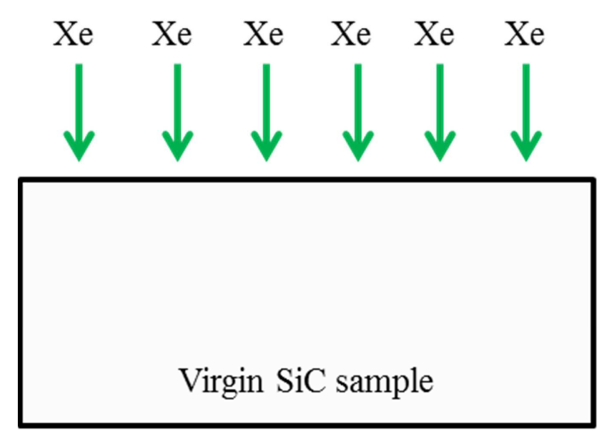

Irradiation start

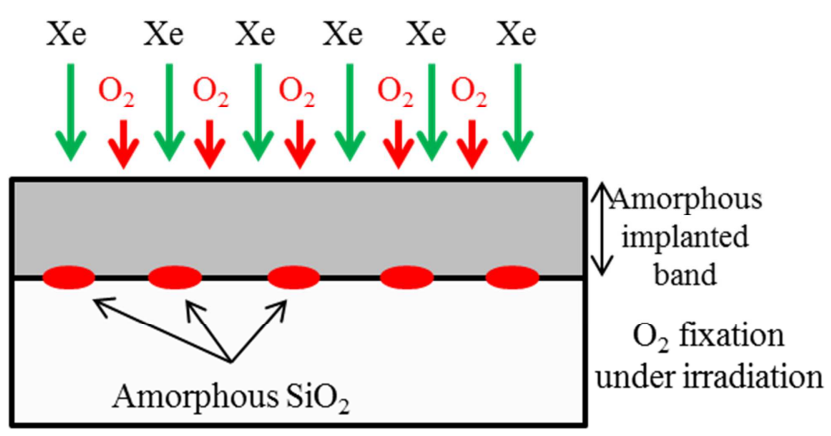

Low fluence $\Phi_{1}$

$$
\mathrm{Xe} \quad \mathrm{Xe} \quad \mathrm{Xe} \quad \mathrm{Xe} \quad \mathrm{Xe} \quad \mathrm{Xe}
$$

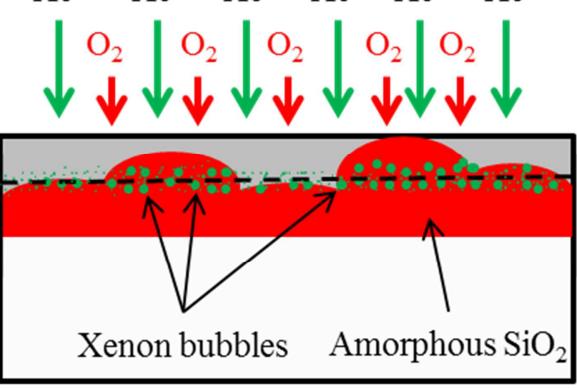

Intermediate fluence $\Phi_{1}<\Phi<\Phi_{2}$

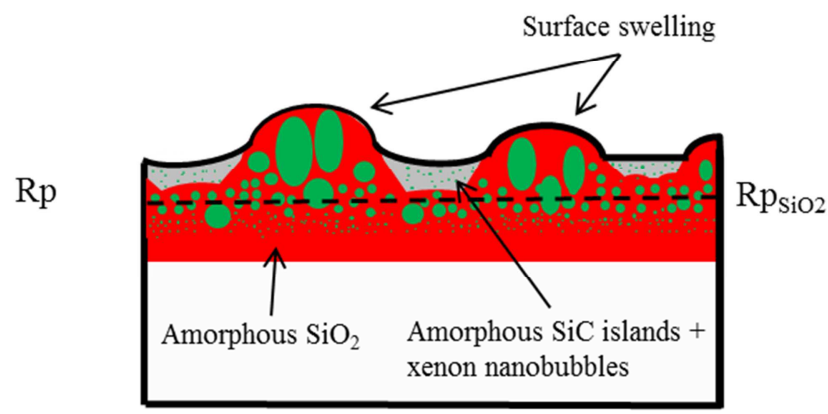

High fluence $\Phi_{2}$

Figure 14: Schematic model of bubble nucleation and oxide growth during xenon implantation in polycrystalline $\beta$-SiC

It is interesting at this stage to compare $\mathrm{SiC}$ behavior with that of $\mathrm{TiC}$ irradiated in similar conditions. It has been shown in a previous work [44] that polycrystalline TiC (submicronic to micrometric grains) is not amorphized by xenon irradiation at RT up to an ion fluence of $1.2 .10^{17} \mathrm{at}_{\mathrm{cm}} \mathrm{cm}^{-2}$ (423 dpa). Nevertheless, nano- or 
micro-cracks are formed at depths near the projected range $\left(\mathrm{R}_{\mathrm{p}} \approx 160 \mathrm{~nm}\right)$ and where lateral extension varies with the size of the considered grain (Fig. 15). Micrometric blisters are clearly visible on the surface just after implantation (see Fig. 15 b)).
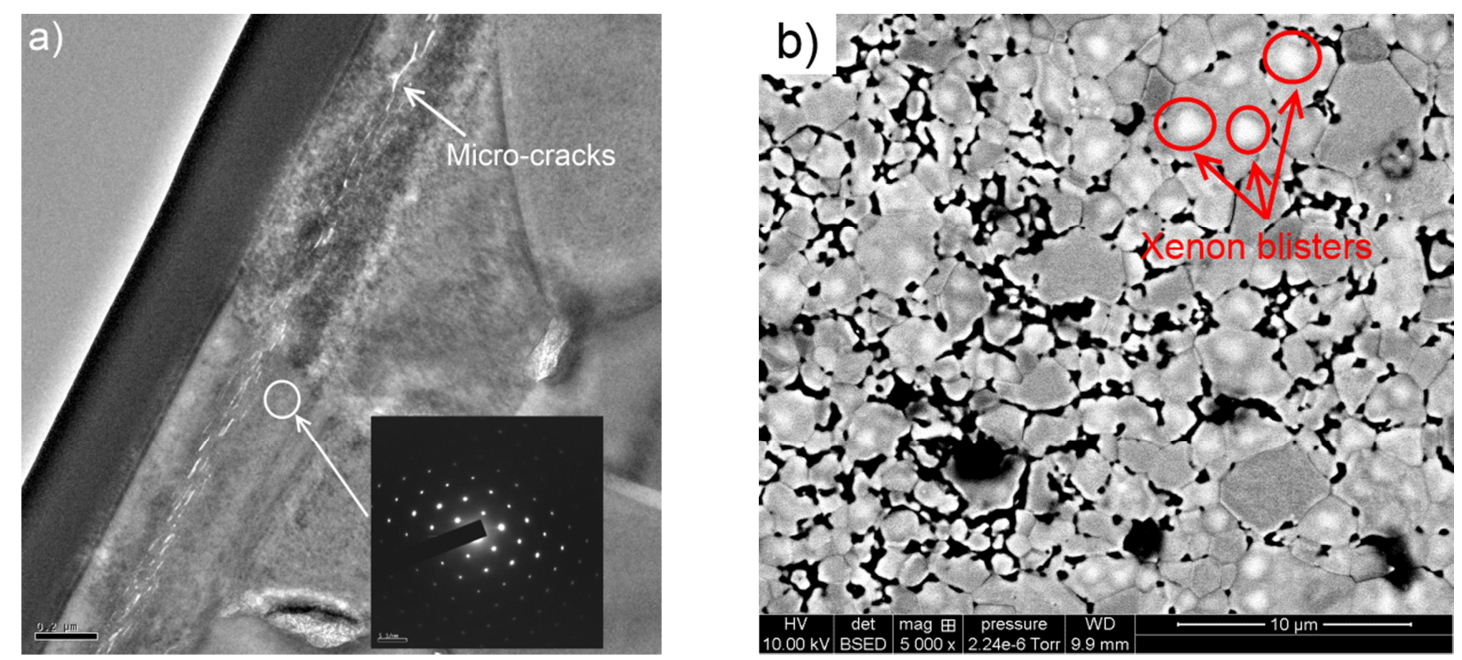

Figure 15: a) TEM image of a TiC cross-section obtained by FIB after Xe RT-irradiation at a fluence of $12.10^{17}$ at.cm $^{-2}$. Surface swelling (blister) and micro-cracks are visible, b) SEM image of surface blisters.

A remarkable fact in the case of Xe-irradiated $\mathrm{SiC}$ is that amorphization, and also the drastic modification of surface composition at high fluence, is not associated with noticeable xenon release. On the other hand, the exfoliation of some blisters and the possible fracturation of the surface under the effect of gas pressure were shown in our previous work to result in a partial release of xenon from crystalline TiC.

The results presented here are of great interest concerning the use of $\mathrm{SiC}$ in nuclear reactors because one of the major roles expected of this compound is that it must prevent fission product release under extreme conditions of irradiation. The next step of this work will be to apply thermal treatments to Xe-implanted $\mathrm{SiC}$ in order to study recrystallisation and its consequence on the distribution of xenon bubbles in the material, and eventually gas release.

Another question which needs to be considered concerns the influence of the temperature imposed during xenon implantation. Irradiation experiments at temperatures comprised between $-195{ }^{\circ} \mathrm{C}$ (cooling with liquid nitrogen) and $+1000{ }^{\circ} \mathrm{C}$ will be performed to evaluate the impact of both oxidation, amorphization and defect healing on xenon behavior in polycrystalline $\beta$-SiC.

\section{Acknowledgments:}

SEM and TEM images were made using the CT $\mu$ facilities (Technological Center of Microstructures: http://microscopies.univ-lyon1.fr/) in the Université de Lyon (France). Our many thanks also go to D. Troadec from the IEMN laboratory (Lille, France) for the fabrication of thin cross-sections. 


\section{References:}

[1] Y. Katoh, L. L. Snead, T. Cheng, C. Shih, W. D. Lewis, T. Koyanagi, T. Hinoki, C. H. Henager Jr, M. Ferraris, J. Nucl. Mater. 448 (2014) 497-511.

[2] Y. Katoh, K. Ozawa, C. Shih, T. Nozawa, R. J. Shinavski, A. Hasegawa, L. L. Snead, J. Nucl. Mater. 448 (2014) 448-476.

[3] D. Guo, H. Zang, P. Zhang, J. Xi, T. Li, L. Ma, C. He, J. Nucl. Mater. 455 (2014) 229-233.

[4]: C.H. Chen, Y. Zhang, E. Fu, Y. Wang, M.L. Crespillo, C. Liu, S. Shannon, W.J. Weber, J. Nucl. Mater. 453 (2014) 280-286.

[5]: A. Ivekovic, S. Novak, G. Drazic, D. Blagoeva, S. Gonzalez de Vicente, Journal of the European Ceramic Society 33 (2013) 1577-1589.

[6]: Y. Ishikawa, S. Nagata, M. Zhao, T. Shikama, J. Nucl. Mater. 455 (2014) 512-515.

[7]: B. Nhiep Nguyen, C. H. Henager Jr., J. Nucl. Mater. 440 (2013) 11-20.

[8] A. Udayakumar, M. Stalin, M. B. Abhayalakshmi, R. Hariharan, M. Balasubramanian, J. Nucl. Mater. 442 (2013) S384-S389.

[9] F. Linez, E. Gilabert, A. Debelle, P. Desgardin, M.-F. Barthe, J. Nucl. Mater. 436 (2013) 150-157.

[10] N. Chaâbane, M. Le Flem, M. Tanguy, S. Urvoy, C. Sandt, P. Dumas, Y. Serruys, J. Nucl. Mater. 439 (2013) 123-130.

[11]: N. Ordas, A. Bereciartu, C. García-Rosales, A. Morono, M. Malo, E. R. Hodgson, J. Abellà, S. Colominas, L. Sedano, Fusion Engineering and Design 89 (2014) 1274-1279.

[12]: Y. Yamamoto, T. Karasawa, Y. Murakami, S. Takemoto, D. Yonetsu, K. Noborio, S. Konishib, Fusion Engineering and Design 89 (2014) 1392-1396.

[13]: T. Koyanagi, K. Ozawa, T. Hinoki, K. Shimoda, Y. Katoh, J. Nucl. Mater. 448 (2014) 478-486.

[14]: L. Gemini, D. Margarone, T. Mocek, F. Neri, S. Trusso, P. M. Ossi, Applied Surface Science 272 (2013) $19-24$.

[15]: Y. Katoh, L. L. Snead, I. Szlufarska, W.J. Weber, Current Opinion in Solid State and Materials Science 16 (2012) 143-152.

[16]: L. Q. Zhang, C. H. Zhang, L. H. Han, C. L. Xu, J. J. Li, Y. T. Yang, Y. Song, J. Gou, J. Y. Li, Y. Z. Ma, Journal of Nuclear Materials 455 (2014) 704-709.

[17] : Q. Wang, C. Wang, Y. Zhang, T. Li, Nuclear Instruments and Methods in Physics Research B 328 (2014) $42-47$. 
[18]: T. J. Gerczak, G. Zheng, K. G. Field, T. R. Allen, Journal of Nuclear Materials 456 (2015) 281-286.

[19] : J. H. O’Connell, J. H. Neethling, Journal of Nuclear Materials 456 (2015) 436-441.

[20] B. S. Li, Y. Y. Du, Z. G. Wang, K. F. Wei, H. P. Zhang, C. F. Yao, H. L. Chang, J. R. Sun, M. H. Cui, Y. B. Sheng, L. L. Pang, Y. B. Zhu, X. Gao, P. Luo, H. P. Zhu, J. Wang, D. Wang, Vacuum 113 (2015) 75-83.

[21]: A. Ravenet, Corps d'assemblage de combustible nucléaire et un assemblage de combustible nucléaire

[22] P. Hazdra, V. Záhlava, J. Vobecky, Nuclear Instruments and Methods in Physics Research B 327 (2014) $124-127$.

[23]: L.L. Snead, T. Nozawa, M. Ferraris, Y. Katoh, R. Shinavski, M. Sawan, J. Nucl. Mater. 417 (2011) 330.

[24] W.-J. Kim, S.M. Kang, K.H. Park, A. Kohyama, W.-S. Ryu, J.Y. Park, J. Korean Ceram. Soc. 42 (2005) 575.

[25] L. L. Snead, T. Nozawa, Y. Katoh, T. S. Byun, S. Kondo, D. A. Petti, J. Nucl Mater (2007) 371-329.

[26] Y. Katoh, A. Kohyama, T. Nozawa, M. Sato, J Nucl Mater 587 (2004) 329-333.

[27] Y. Katoh, L. L. Snead, C. H. Henager, A. Hasegawa, A. Kohyama, B. Riccardi, J. Nucl Mater 659 (2007) 367-370.

[28] J. B. Malherbe, N.G. van der Berg, A. J. Botha, E. Friedland, T. T. Hlatshwayo, R. J. Kuhudzai, E. Wendler, W. Wesch, P. Chakraborty, E. F. da Silveira, Nuclear Instruments and Methods in Physics Research B 315 (2013) 136-141.

[29] V. Yu. Fominski, S. N. Grigoriev, R. I. Romanov, A. G. Gnedovets, P. N. Chernykh, Nuclear Instruments and Methods in Physics Research B 313 (2013) 68-75.

[30] K. Jin, Y. Zhang, H. Xue, Z. Zhu, W. J. Weber, Nuclear Instruments and Methods in Physics Research B 307 (2013) 65-70.

[31] J.-F. Barbot, M.-F. Beaufort, A. Declémy, Nuclear Instruments and Methods in Physics Research B 327 (2014) 59-62.

[32] L. L. Snead, K. A. Terrani, Y. Katoh, C. Silva, K. J. Leonard, A. G. Perez-Bergquist, Journal of Nuclear Materials 448 (2014) 389-398.

[33] Y. Lee, T. J. McKrell, C. Yue and M. S. Kazimi, Nuclear Technology 183 (2013) 210-227.

[34] S.J. Zinkle, C. Kinoshita, J. Nucl. Mat. 251 (1997) 200.

[35] A. Debelle, L. Thomé, D. Dompoint, A. Boulle, F. Garrido, J. Jagielski, D. Chaussende, J. Phys. D: Appl. Phys. 43 (2010) 455408.

[36] M.F. Beaufort, F. Pailloux, A. Declémy, J.F. Barbot, J. Appl. Phys. 94 (2003) 7116. 
[37] J.F. Barbot, M.F. Beaufort, M. Texier, C. Tromas, J. Nucl. Mater. 413 (2011) 162.

[38] S. Miro, J.M. Costantini, J. Haussy, L. Beck, S. Vaubaillon, S. Pellegrino, C. Meis, J.J. Grob, Y. Zhang, W.J. Weber, J. Nucl. Mater. 415 (2011) 5

[39] A. Charaf Eddin and L. Pizzagalli, J. Nucl. Mater., 429 (2012) 329-334

[40] E. Friedland, K. Gärtner, T. T. Hlatshwayo, N. G. van der Berg, T. T. Thabethe, Nuclear Instruments and Methods in Physics Research B 332 (2014) 415-420.

[41]: W. J. Weber, L. M. Wang, Nuclear Instruments and Methods in Physics Research Section B: Beam Interactions with Materials and Atoms, 106 (1995) 298.

[42]: A. Föhl, R. M. Emrick, H. D. Carstanjen, Nuclear Instruments and Methods in Physics Research Section B: Beam Interactions with Materials and Atoms, 65 (1992) 335.

[43]: G. Velisa, A. Debelle, L. Thomé, S. Mylonas, L. Vincent, A. Boulle, J. Jagielski, D. Pantelica, Journal of Nuclear Materials 451 (2014) 14-23.

[44]: S. Gavarini, N. Millard-Pinard, V. Garnier, M. Gherrab, J. Baillet, L. Dernoncourt, C. Peaucelle, X. Jaurand, T. Douillard, Nuclear Instruments and Methods in Physics Research B 356-357 (2015) 114-128.

[45]: Y. Leconte, H. Maskrot, L. Combemale, N. Herlin-Boime, C. Reynaud, J. Anal. Appl. Pyrolysis 79 (2007) 465-470.

[46]: B. Lanfant, Y. Leconte, G. Bonnefont, V. Garnier, Y. Jorand, S. LeGallet, M. Pinault, N. Herlin-Boime, F. Bernard, G. Fantozzi, Journal of the European Ceramic Society 35 (2015) 3369-3379.

[47]: F. Lomello, G. Bonnefont, Y. Leconte, N. Herlin-Boime, G. Fantozzi, Journal of the European Ceramic Society 32 (2012) 633-641.

[48]: Rasband, W.S., ImageJ, U. S. National Institutes of Health, Bethesda, Maryland, USA, http://imagej nih.gov/ij/, 1997-2016.

[49]: M. Mayer, Nucl. Instr. Meth. B 194 (2002) 177-186.

[50]: M. Mayer, RESOLNRA: A new program for optimizing the achievable depth resolution of ion beam analysis methods, Nucl. Instr. Methods B, 266 (2008) 1852-1857.

[51]: A. Chevarier, N. Chevarier, M. El Bouanani, E. Gerlic, M. Stern, B. Roux, F. Thimon, Appl. Surf. Sci. 215 (1991) 48-49.

[52]: The Stopping and Range of Ions in Matter, J.F. Ziegler, J.P. Biersack, M.D. Ziegler, SRIM Co. (2008) and WWW.SRIM.org

[53]: S. Muto, H. Sugiyama, T. Kimura, T. Tanabe, T. Maruyama, Nucl. Instr. Methods B, 218 (2004) 117-122. 
[54]: A. Naas, E. Ntsoenzok, D. De Sousa-Meneses, B. KHakim, A. Beya-Wakata, Nuclear instruments and Methods, B 339 (2014) 46-52. 